\title{
A scientific note on using large mixed sperm samples in instrumental insemination of honeybee queens
}

\author{
Johanna T. Pieplow ${ }^{1}$, Jürgen BraußE ${ }^{2}$, Jacob P. van PraAgh $^{3}$, Robin F. A. Moritz ${ }^{1,4,5}$, Silvio Erler ${ }^{1}$ \\ ${ }^{1}$ Institut für Biologie, Molekulare Ökologie, Martin-Luther-Universität Halle-Wittenberg, Hoher Weg 4, 06099, Halle (Saale), \\ Germany \\ ${ }^{2}$ Blankenseer Dorfstraße 2, 14959, Trebbin, OT Blankensee, Germany \\ ${ }^{3}$ Hassellstraße 23, 29223, Celle, Germany \\ ${ }^{4}$ Department of Zoology and Entomology, University of Pretoria, Pretoria 0002, South Africa \\ ${ }^{5}$ German Centre for Integrative Biodiversity Research (iDiv) Halle-Jena-Leipzig, Deutscher Platz 5e, 04103, Leipzig, Germany
}

Received 22 November 2016 - Revised 28 March 2017 - Accepted 27 April 2017

artificial insemination / bee breeding / Apis mellifera / homogenous mixing / genetic diversity

Instrumental insemination of queen honeybees has become a routine technology in honeybee breeding (Laidlaw 1944). The technique overcomes the problems resulting from lack of rigorous mating control under natural conditions. The queen is typically inseminated with semen from 8 to 12 drones (Cobey et al. 2013). Often, bee breeders cross a queen with drones of a single 'father' lineage to achieve their selection goals. However, this process imposes extreme constraints on the genotypic composition of the colony. The queen naturally mates with many unrelated males resulting in genotypically much more diverse colonies than after instrumental insemination. High intra-colonial genotypic variance among the workers has been shown to be beneficial for colony efficiency (Tarpy and Seeley 2006; Mattila and Seeley 2007). As genotypically distinct workers specialize in different tasks, reduced genetic variance may negatively impact on division of labour in the colony as well (Lattorff and Moritz 2013). If the combination of specific genotypes results in the desired colony trait, it might be useful to inseminate a queen with a set of drones from different lineages instead of a single one. Workers of the various patrilines

Electronic supplementary material The online version of this article (doi:10.1007/s13592-017-0516-4) contains supplementary material, which is available to authorized users.

Corresponding author: S. Erler, erler.silvio@gmail.com Manuscript editor: David Tarpy in such a multi-lineage colony might complement each other to release a more efficient colony phenotype.

In order to produce such 'custom design' colonies, it will however be necessary to reliably reproduce suitable sperm mixes to inseminate the queens. Using individual drones to inseminate a queen will be insufficient. Another queen will be inseminated with a set of semen from different drones. Hence, no single colony will have identical fathers unlike classical animal breeding, where a single siring male can be mated to many females. The replication of the insemination is not possible, which dilutes any assessment of breeding values. Here, we use a new technique for mixing of semen from a very large pool comprising thousands of drones (Brauße and van Praagh 2010) to test if these can be homogeneously mixed and used for replicate inseminations.

The semen of 2037 drones (204 \pm 34 per colony) from 10 unrelated honeybee colonies was collected and mixed according to Brauße and van Praagh (2010) resulting in $960 \mu \mathrm{L}$ mixed semen. Three virgin queens were instrumentally inseminated with $10 \mu \mathrm{L}$ aliquots of the sperm mix and allowed to produce worker offspring. When the colonies were in full brood production, 32 pupae were sampled from each colony for genotyping. Additionally, semen of one drone from each of the 10 drone producing colonies was sampled for individual genotyping and lineage identification. All samples (sperm and brood) were stored in $70 \%$ ethanol till DNA extraction.

The sperm samples were centrifuged for $15 \mathrm{~min}$ at $20,800 \mathrm{~g}$, the pellets washed twice in $500 \mu \mathrm{L}$ distilled 
a

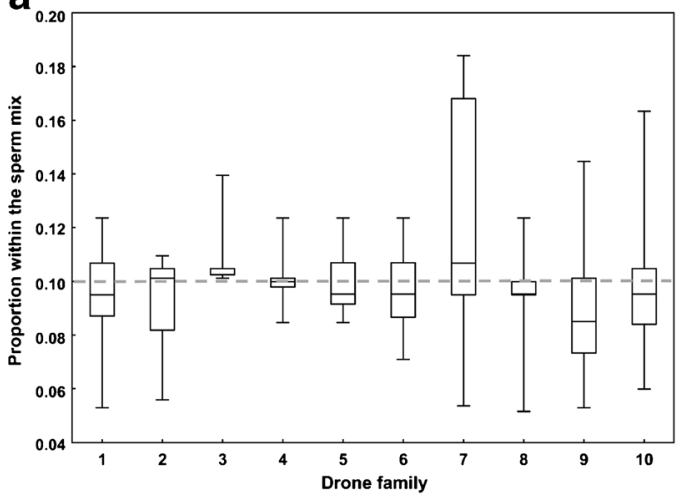

b

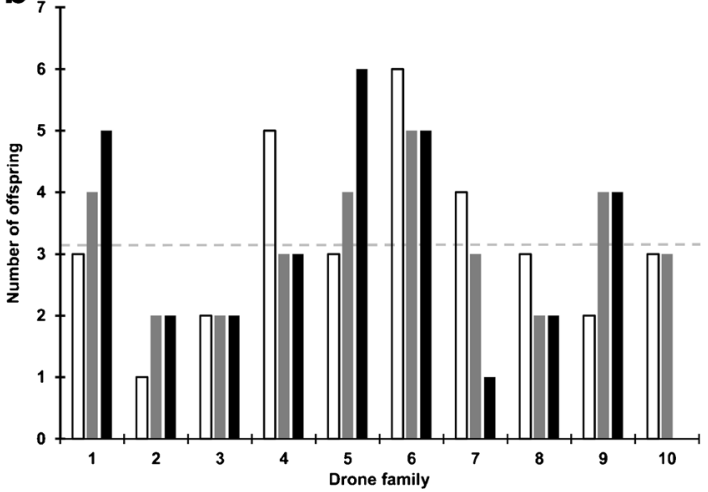

Figure 1. a Distribution of drone families within the sperm mix (median with box 25-75\% range, and whisker: min-max range, dotted grey line: expected even distribution). b Absolute number of pupae sired by each drone lineage in the three natal colonies (white: colony A $\left(n_{\text {total }}=32\right)$, filled grey: colony B $\left(n_{\text {total }}=32\right)$, filled black: colony $\mathrm{C}\left(n_{\text {total }}=30\right)$, dotted grey line : expected even distribution). None of the distributions (colony A-C) deviated significantly from an even distribution (Fisher's exact tests, $P>0.05$ ).

water for $1 \mathrm{~h}$, and dried at $37{ }^{\circ} \mathrm{C}$. DNA was extracted following the DNeasy Blood \& Tissue Kit (QIAGEN) protocol but with $40 \mu \mathrm{L} 1 \%$ Proteinase K (instead of $20 \mu \mathrm{L}$ ) and incubation at $56^{\circ} \mathrm{C}$ for $12 \mathrm{~h}$. Two legs of each worker pupa were used for DNA extraction, using a modified Chelex protocol (Walsh et al. 1991) as described by Erler and Lattorff (2010). Genotyping details, using five highly polymorphic loci, are given in the Online Resource.

Maternal and paternal genotypes of every worker pupae could be unambiguously assigned by Mendelian inference. The siring drones were assigned to one of the 10 drone providing queens in the semen mix, based on the genotypic information from the single sperm samples (Online Resource Table SI, SII). Further details on allele identification in the sperm mix and statistics are given in the Online Resource.

The marker set used was sufficiently sensitive to address the problem with a non-detection error of $3.4 \times 10^{-3}$ (Boomsma and Ratnieks 1996). None of the 10 lineages was significantly over- or underrepresented neither in the sperm mix (Figure 1a; Kruskal-Wallis test $H=4.13, d f=9, P=0.90$ ) nor in the comparison offspring worker pupae vs. sperm mix $\left(\chi^{2}=14.23, d f=9, P=0.11\right.$; power of 0.85 ) (Figure 1 $\mathrm{a}, \mathrm{b})$. The distribution of drone lineages among the offspring worker pupae did not significantly differ from an expected even distribution $\left(\chi^{2}=12.38, d f=9\right.$, $P=0.19$; power of 0.87 ). Finally, there were no significant differences among the three analysed colonies regarding the drone lineage distribution (Fisher exact test $n=94, P=0.97$; power of 1.0) (Figure 1b).
Neither the distribution of drone lineages within the sperm mix nor the distribution among the offspring worker pupae differed significantly from an even distribution. The repeatability of the technique among the three queens was remarkable with $r=0.45$ (Boake 1989). We expect this to be stable over time as any patriline clustering of sperm after having been mixed seems biologically most unlikely (Page et al. 1984). Large volume sperm mixing may set the stage to implement novel breeding strategies. It allows for homogenous mixing of $3000 \mu \mathrm{L}$ sperm (approx. 7000 drones), sufficient to inseminate up to 250 honeybee queens (van Praagh et al. 2014). The technique may set the stage to establish custom design colonies not just for honey production but also for other colony phenotypes of apicultural interest.

\section{ACKNOWLEDGEMENTS}

Financial support was granted by the Brandenburg State Agency for Rural Development, Agriculture and Land Consolidation to the HOSIMET (Homogenous sperm mixing technology in Europe-wide Varroa Tolerance Breeding) breeding program (State association of Buckfast beekeepers Berlin-Brandenburg e.V.). Further, we thank C. Orzessek and P. Leibe for help with the lab work, and H.M.G. Lattorff for sharing data on primer polymorphism and heterozygosity across several Apis mellifera sub-species.

Contributions JPvP, JB, RFAM and SE conceived this research; JTP, RFAM and SE interpreted the data; JTP and 
SE performed experiments and analysis; All authors wrote the paper and participated in the revisions of it.

Note scientifique sur l'utilisation de grands échantillons d'un mélange de spermes pour l'insémination artificielle de reines d'abeilles

\section{Eine wissenschaftliche Notitz zur Verwendung großer Spermaproben bei der instrumentellen Besamung von Honigbienenköniginnen}

\section{REFERENCES}

Boake, C.R.B. (1989) Repeatability: its role in evolutionary studies of mating behaviour. Evol. Ecol. 3, 173-182

Boomsma, J.J., Ratnieks, F.L.W. (1996) Paternity in eusocial Hymenoptera. Philos. T. Roy. Soc. B. 351, 947-975

Brauße, J., van Praagh, J.P. (2010) Stirring large volumes of pooled honeybee semen. Proc. Neth. Entomol. Soc. Meet. 21, 49-53

Cobey, S.W., Tarpy, D.R., Woyke, J. (2013) Standard methods for instrumental insemination of Apis mellifera queens, In: Dietemann, V., Ellis, J.D. and Neumann, P. (Eds.), The COLOSS BEEBOOK, Volume I: Standard methods for Apis mellifera research. J. Apic. Res. 52, 1-18, DOI: 10.3896 /IBRA.1.52.4.09

Erler, S., Lattorff, H.M.G. (2010) The degree of parasitism of the bumblebee (Bombus terrestris) by cuckoo bumblebees (Bombus (Psithyrus) vestalis). Insectes Soc. 57, 371-377

Laidlaw, H.H. (1944) Artificial insemination of the queen bee (Apis mellifera L.): Morphological basis and results. J. Morphol. 74, 429-465

Lattorff, H.M.G., Moritz, R.F.A. (2013) Genetic underpinnings of division of labor in the honeybee (Apis mellifera). Trends Genet. 29, 641-648

Mattila, H.R., Seeley, T.D. (2007) Genetic diversity in honey bee colonies enhances productivity and fitness. Science $317,362-$ 364

Page, R.E., Kimsey, R.B., Laidlaw, H.H. (1984) Migration and dispersal of spermatozoa in spermathecae of queen honeybees (Apis mellifera L.). Experientia 40, 182-184

Tarpy, D.R., Seeley, T.D. (2006) Lower disease infections in honeybee (Apis mellifera) colonies headed by polyandrous vs monandrous queens. Naturwissenschaften 93, 195-199

van Praagh, J.P., Brauße, J., Titera, D. (2014) Mixing and storing large volumes of honeybee (Apis mellifera mellifera L.) sperm integrated in a breeding program. Proc. Neth. Entomol. Soc. Meet., 25, 39-45

Walsh, P.S., Metzger, D.A., Higuchi, R. (1991) Chelex-100 as a medium for simple extraction of DNA for PCR-based typing from forensic material. Biotechniques 10, 506-513 